ISSN 2236-0859

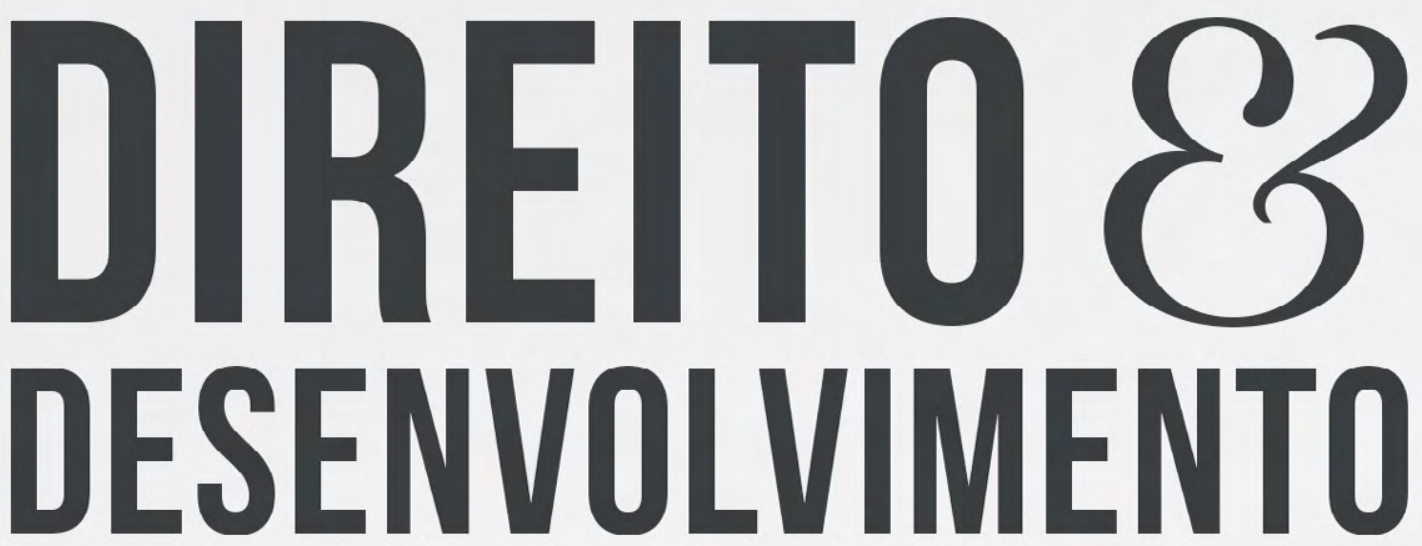

REVISTA DO PROGRAMA DE PÓS-GRADUAÇÃO EM DIREITO MESTRADO EM DIREITO E DESENVOLVIMENTO SUSTENTÁVEL

IMPACTOS DA CONSTITUICÃO BRASLLEERA DE 1988 NA TRAJETÓRIA DO DESENVOLVIMENTO DO NORDESTE

GERARDO CLÉSIO MAIA ARRUDA

LUIS AUGUSTOBEZERRA MATTOS 


\title{
IMPACTOS DA CONSTITUIÇÃO BRASILEIRA DE 1988 NA TRAJETÓRIA DO DESENVOLVIMENTO DO NORDESTE
}

\section{IMPACTS OF THE BRAZILIAN CONSTITUTION OF 1988 IN THE DEVELOPMENT TRAJECTORY OF THE NORTHEAST}

Recebido: 13/02/2018

Aprovado: 04/04/2018
Gerardo Clésio Maia Arruda* Luis Augusto Bezerra Mattos**

RESUMO: Neste artigo busca-se verificar os reflexos da constitucionalização do combate às desigualdades regionais para o desenvolvimento do Nordeste. Para tanto, explicita-se a estrutura legislativa e institucional anterior à Constituição de 88, as ações estatais mais relevantes e os obstáculos que frearam os resultados planejados. Em seguida, realiza-se uma análise dos resultados das políticas públicas adotadas, principalmente, nas duas décadas seguintes à promulgação da Carta Cidadã, concernentes à melhoria das condições socioeconômicas da população nordestina. Adotou-se uma abordagem histórica apoiada na literatura que trata da regulamentação do desenvolvimento e em estudos sobre as políticas públicas direcionadas ao crescimento econômico e à redução da pobreza. Conclui-se que a Constituição de 88 proporcionou a execução de ações estatais que promoveram o desenvolvimento do Nordeste, mas que ainda se demanda um esforço hercúleo para reduzir o hiato que separa o Nordeste da região Sudeste.

Palavras-chave: Constituição de 1988. Desenvolvimento. Nordeste.

\begin{abstract}
This article seeks to verify the reflexes of the constitutionalization of the fight against regional inequalities for the development of the Northeast. In order to do so, the legislative and institutional structure prior to the Constitution of 1988 , the most relevant state actions and the obstacles that hampered the planned results are made explicit. Then, an analysis of the results of the public policies adopted, mainly, in the two decades following the promulgation of the Citizen Charter, concerning the improvement of the socioeconomic conditions of the Northeastern population. We adopted a historical approach based on the literature on development regulation and on public policy studies aimed at economic growth and poverty reduction. It is concluded that the Constitution of 1988 provided for the execution of state actions that promoted the development of the Northeast, but that a Herculean effort is still required to reduce the gap that separates the Northeast from the Southeast.
\end{abstract}

Keywords: Constitution of 1988. Development. Northeast.

\footnotetext{
1 * Professor do Programa de Mestrado em Direito do Centro Universitário Christus (UNICHRISTUS) e Professor Titular da Universidade de Fortaleza (UNIFOR). Doutor e Mestre em Sociologia, Especialista em Geografia e Graduado em Ciências Econômicas. E-mail: clesioarruda@yahoo.com.br

2 ** Mestrando em Direito, Acesso e Desenvolvimento, pelo Centro Universitário Christus (UNICHRISTUS), Especialista em Direito Processual Constitucional e Graduado em Direito. E-mail: luis_abm@hotmail.com
} 


\section{INTRODUÇÃO}

A ideia do Nordeste brasileiro como um local inóspito, incapaz de gerar riqueza, foi uma construção que teve na obra $\mathrm{O}$ sertanejo, de José de Alencar (2013), publicada originalmente no ano de 1875, o seu marco literário; no campo científico, Carl Friedrich Philip Von Martius, médico, botânico e antropólogo, que chegou ao Brasil na comitiva da Duquesa austríaca Leopoldina, e empreendeu viagem pelo interior do Brasil, no período de 1817 a 1820, foi o precursor dos estudos que generalizaram a região como inapta à produção de riqueza (ARRUDA, 2005).

Entretanto, Euclides da Cunha (1979), com a obra Os sertões, publicada em 1902, foi o autor que se projetou como o construtor da ideia do Nordeste miserável, tanto no imaginário popular quanto nas assertivas científicas, ao delimitar este espaço geográfico do Brasil como um lugar castigado pelo sol inclemente, dos períodos de prolongadas estiagens, da fome, da miséria. Uma ideia que tomou corpo e se difundiu a partir dos romances regionalistas, podendo-se citar O quinze, de Raquel de Queiroz (1993) e Vidas secas, de Graciliano Ramos (1998). Trabalhos científicos também foram formulados a partir deste viés e reproduziram assertivas semelhantes, como o do geógrafo Manuel Correia de Andrade (1986) e do sociólogo e antropólogo francês Roger Bastide (1959).

Outros olhares se opuseram a esta generalização do Nordeste miserável e distinguiram espaços de produção de riqueza, mesmo na área concernente ao semiárido, fato este já existente antes mesmo da industrialização e do surgimento das metrópoles. O historiador Nobre (1989) chama a atenção para a produção do algodão que, em alguns momentos, gerou mais recursos do que a exportação do açúcar; além do que aponta a existência de elevadas somas arrecadadas no sertão nordestino, com base no interesse internacional, que perdurou do período do surgimento das grandes indústrias até a Segunda Grande Guerra, relativas à produção de óleos vegetais, extraídos da mamona, da amêndoa do babaçu e do caroço do algodão. Arruda (2003), por sua vez, salienta o capital produzido e acumulado pelos criadores de gado no sertão, que combinavam a atividade da criação extensiva para a exportação da carne e do couro com a atividade comercial nas vilas e cidades sertanejas.

O Nordeste miserável é uma representação construída que funcionou para escamotear a dominação que se exercia sobre trabalhadores rurais, ao naturalizar a miséria da terra e, por conseguinte, a do homem, assim tornando invisível a formação de capital e a sua acumulação concentrada, produzida em todas as subáreas geográficas do Nordeste, compreendendo a zona da mata, do agreste, sertão e meio norte. Uma riqueza construída apesar da baixa produtividade das atividades econômicas, principalmente quando comparada com a região sudeste, como foi exemplarmente diagnosticado pelo economista Celso Furtado (2007). Saliente-se ainda, como demonstrado pelo sociólogo Francisco de Oliveira (1981), que nesta economia de baixa produtividade a acumulação da riqueza era apropriada por uma minoria, o que resultava em efeitos danosos para o conjunto da população nordestina.

Com efeito, os esforços científicos empreendidos na busca de demonstrar a combinação, neste espaço geográfico nacional, de produção de riqueza e miséria, transformaram a região Nordeste em "questão social" brasileira prioritária. Este fato impulsionou o debate político nacional sobre as fórmulas ideais para o seu enfrentamento. Uma discussão que se encontra na base da proposição do rearranjo institucional dos órgãos federais e estaduais com atuação na região, efetivado em meados do século XX, e a positivação Constitucional, em 1988, direcionada para a redução da desigualdade regional.

Neste artigo, busca-se justamente averiguar os efeitos da constitucionalização do combate à desigualdade social e regional, concomitantemente, às regulações que redirecionaram a dinâmica e as ações das instituições voltadas para o desenvolvimento da região Nordeste, como a Superintendência de Desenvolvimento do Nordeste (SUDENE), Banco do Nordeste do Brasil (BNB), e o Fundo Nacional de Investimento do Nordeste (FINOR). Também, procura aferir se a efetivação dos dispositivos 
constitucionalmente previstos e as regulamentações ordinárias visando ao desenvolvimento regional foram capazes de alterar positivamente a realidade socioeconômica do Nordeste. Enfim, busca-se neste artigo contribuir para a produção de uma agenda político-jurídico que mantenha acesa a chama do entusiasmo que movimentou os debates da Assembleia Nacional Constituinte de 1987/88 acerca dos temas da pobreza, da desigualdade e do desenvolvimento regional.

\section{AÇÕES ESTATAIS PARA O DESENVOLVIMENTO DO NORDESTE ANTERIORES À CONSTITUIÇÃO DE 1988}

A intervenção do Estado no Nordeste é compreendida em sua lógica e historicidade quando observada vis-à-vis a sua formação econômica, que de forma ampla se deu com base na economia açucareira, praticada na parte mais oriental, e na economia de subsistência, que se desenvolveu no interior da região e produzia, predominantemente, alimentos e animais para transporte, visando ao abastecimento das fazendas canavieiras e dos engenhos de açúcar. A combinação destes segmentos formulou uma economia dependente do mercado internacional e alicerçada na propriedade do latifúndio, e assim como emergiu o "barão" do café, na região sudeste, deu-se no Nordeste o aparecimento do "barão" do açúcar e o "coronel" da fazenda de gado e do algodão. O poder unitário do Segundo Império e da República Velha se reproduziu na região nordestina, como legitimador de uma política que garantia os lucros obtidos com a exportação, de sorte que as ações estatais, sob o controle de "barões" e "coronéis", visavam à manutenção da estrutura fundiária e da forma da exploração da força de trabalho, que se constituíam na base da manutenção dos ganhos. (OLIVEIRA, 1981)

A Inspetoria de Obras Contra as Secas (IOCS), criado no ano de 1909, posteriormente denominada Inspetoria Federal de Obras Contra as Secas (IFOCS) e, por fim, no ano de 1945, Departamento Nacional de Obras Contra as Secas (DNOCS), foi instituída via decreto n. 8.846, com os seguintes objetivos funcionais: (I) a construção de estradas de ferro e rodagem; (II) a instalação de açudes e de sistemas de irrigação; (III) o plantio de vegetação resistente à seca; e (IV) sistematização de estudos das condições metereológicas, geológicas e topográficas das zonas atingidas pelo fenômeno da seca. (BRASIL, 2016). As ações estatais aí inauguradas são reconhecidas como sendo as primeiras intervenções racionais, fruto de estudos e pesquisas, realizadas no Nordeste. Ressalte-se que estes órgãos, de acordo com Oliveira (1977), foram pensados originalmente para atuarem em todo o território nacional, mas o poder oligárquico, principalmente vinculado às fazendas de gado-algodão, apropriou-se de seus funcionamentos e limitaramnos, executivamente, a região do semiárido.

A coexistência de poderes locais com um forte poder central não é contraditória, no entendimento de Bursztyn (1984), o mandonismo local dos "coronéis" do sertão funcionou como uma sustentação, associado ao autoritarismo praticado nas demais regiões do país, para o poder central, que em troca garantia a permanência da estrutura socioeconômica piramidal, em que alguns poucos detinham uma riqueza que os distanciavam do grosso da população situada na sua base. Neste sentido, as racionalizações que, por lógica, deveriam promover alterações na estrutura produtiva e, por conseguinte, na forma de apropriação da produtividade, na verdade, mantiveram intactas as bases do modo de produção e da acumulação de capital, extremamente desigual na região nordestina. De sorte que, nos quarenta anos, aproximadamente, de atuação do governo federal, quase exclusivamente por intermédio do DNOCS, não se alterou a realidade social do Nordeste, nem mesmo minimizaram-se os efeitos danosos das secas sobre os proprietários de minifúndios e trabalhadores agrícolas sem-terra.

O período getulista, que marcou uma inflexão na organização da produção do país, deu início a uma mudança na qualidade da ação do Estado no Nordeste. Entretanto, observe-se que a modernização trazida por Getulio Vargas não promoveu alteração na estrutura de produção e nem, principalmente, na estrutura do poder patriarcal local que manteve sua essência inabalável. A criação do Instituto do Açúcar 
e do Álcool (IAA) é uma demonstração de como a oligarquia nordestina se apropriou das ações estatais para garantir as formas tradicionais de exploração na relação capital-trabalho e latifúndio-minifúndio. Como afirma Bursztyn (1984), assim como o DNOCS, o funcionamento do IAA não promoveu alteração no establishment da região.

Pode-se afirmar que a Companhia Hidro Elétrica do São Francisco (CHESF), criada em 1945, por meio do Decreto 8.031, no esteio das ações varguistas de construção da base industrial do país, trata-se da primeira iniciativa relevante direcionada para o fortalecimento da infraestrutura produtiva da região Nordeste. A regulamentação deste órgão expressa este objetivo institucional no Art. $1^{\circ}$, onde se lê que o Ministério da Agricultura fica autorizado a constituir a CHESF, na forma de sociedade por ações, que em seu funcionamento se obriga "a realizar o aproveitamento industrial progressivo da energia hidráulica do Rio São Francisco." Não obstante a missão primeira de produzir, transmitir e comercializar energia elétrica para oito estados do Nordeste: Bahia, Sergipe, Alagoas, Pernambuco, Paraíba, Rio Grande do Norte, Ceará e Piauí, o fato deste órgão vincular-se administrativamente ao Ministério da Agricultura tornou-o, na prática, um órgão operacional auxiliar nas ações estatais para o desenvolvimento do setor agrícola e da pecuária.

O Banco do Nordeste do Brasil (BNB) e a Superintendência do Desenvolvimento do Nordeste (SUDENE) constituem-se nas organizações estatais que, em meados do século XX, imprimiram uma mudança na paisagem do Nordeste, ao deslocarem a centralidade de sua economia da zona rural para as áreas urbanas, que foram paulatinamente tornando-se centros industrializados e de serviços. Isto porque suas missões institucionais, embora contribuam para a modernização dos setores econômicos primários, são marcadamente voltadas para a criação e o apoio de empreendimentos industriais, além das atividades de comércio e serviços auxiliares da produção de manufaturados.

Seguindo a ordem de criação e início de atuação destas duas instituições, ressalte-se que o BNB foi criado pela Lei 1.649, em 19 de julho/1952, no governo Getúlio Vargas. De forma sucinta, em seu artigo 8o da lei supracitada, encontra-se a atividade primordial deste órgão: "o Banco do Nordeste do Brasil prestará assistência, mediante empréstimo, a empreendimentos de caráter reprodutivo, na área do Polígono das secas". Vê-se aí que a prioridade institucional é o incentivo a industrialização e, por conseguinte, a geração de emprego e renda nas áreas onde predominam atividades econômicas de baixa produtividade, principalmente, por intermédio da concessão de auxílio financeiro aos empreendimentos caracteristicamente de transformação. Ainda no que se refere à atuação deste banco estatal, tem-se como atividade fim de seu funcionamento, grosso modo, a proposição de ações voltadas para o desenvolvimento econômico e social.

A SUDENE, por sua vez, criada sob os auspícios da Lei 3.692, em 15 de dezembro/1959, de acordo com a explicação de Souza (2012, p. 593), tem "a finalidade de promover o desenvolvimento inclusivo e sustentável na sua área de atuação e a integração competitiva da base produtiva regional na economia nacional e internacional". Portanto, definiu-se como sua atribuição precípua o combate à exclusão social no perímetro da região Nordeste, bem como a redução das desigualdades internas, por intermédio de uma equiparação das condições de sobrevivência e da qualidade de vida, entre as subáreas, cidades e municípios. Ao avaliar a atuação da SUDENE, Pereira (1988, p. 85) explicita que: "o papel da SUDENE foi de interromper o processo de agravamento das diferenças regionais, não de eliminá-lo”.

O Banco Nacional de Desenvolvimento Econômico (BNDE) foi criado no ano de 1971, pela Lei 5.662, no arcabouço da reforma institucional, na esfera federal, realizada pelo Governo Militar, caracteristicamente concentrador do planejamento e do controle das ações estatais executadas em todo o território nacional. Assim, na engenharia organizacional, deste governo, delimitou-se este órgão como uma empresa pública vinculada ao Ministério do Planejamento e Coordenação Geral. A inversão do sinal que esvaziava a capacidade das regiões, estados e municípios de planejar endogenamente seus desenvolvimentos, aparece no escopo normativo instituidor do BNDE. Isto é observado no artigo $5^{\circ}$, da Lei 5662 , onde se constata a tendência à concentração do planejamento da economia do país pelo Governo Federal, de modo que se determinava como missão institucional do BNDE o controle das operações bancarias que visavam à promoção do 
"desenvolvimento da economia nacional, nos setores e com as limitações consignadas no seu orçamento de investimentos".

Com o surgimento do BNDE, as ações do Banco do Nordeste passaram a ser executadas em parcerias com a esfera do poder federal, ou seja, o BNDE assumiu o papel de braço operacional do desenvolvimento nacional, portanto, também se apresentava como fomentador do desenvolvimento do Nordeste. Como indica Souza (2012, p. 606), enquanto agência federal de financiamento com abrangência em todo território nacional, "o BNDE administra vários programas de fomento do governo nas áreas agropecuária, industrial, social, dentre outras, e, para isso, a agência conta com diversas fontes de recursos federais".

O Fundo de Investimento do Nordeste (FINOR), criado pelo Decreto-Lei 1.376, foi instituído para fortalecer as ações do Banco do Nordeste (BNB) e da Superintendência de Desenvolvimento do Nordeste (SUDENE). Em poucas palavras, pode-se dizer que seu objetivo é o de fortalecer, nas áreas de atuação do BNB e da SUDENE, o desenvolvimento, por se tratar de investimento atrativo para as empresas contribuintes do imposto de renda. Outrossim, o FINOR foi pensado e instituído para reforçar as ações de desenvolvimento do Nordeste a partir de políticas fiscais, uma vez que, segundo Souza (2012, p. 615), “o FINOR era o resultado do benefício fiscal concedido pelo governo federal às empresas contribuintes do Imposto de Renda na modalidade lucro real, na forma de devolução de parte do imposto em cotas de fundo."

Esta estrutura institucional, formatado entre o governo de Juscelino Kubitschek e o Governo Militar, possibilitou a elaboração e a execução de políticas públicas dirigidas para o desenvolvimento do Nordeste. Entretanto, a estrutura organizacional delineada para a ação estatal nesta região, direta ou indiretamente, resulta do impacto ocasionado, no meio técnico-científico e no político, dos estudos do Grupo de Trabalho para o Desenvolvimento do Nordeste (GTDN), um corpo de acadêmicos e pesquisadores que, posteriormente, emprestou organicidade e funcionalidade para a SUDENE.

É consenso entre os estudiosos da economia política e das políticas públicas do Nordeste que o relatório produzido pelo GTDN, na década de 1950, se trata do marco instituidor da análise técnicocientífica do Nordeste. Demais, após mais de meio século de sua publicação, o relatório continua sendo recepcionado como principal diagnóstico da região, como exemplo, cita-se aqui os pesquisadores Cláudia Passador e João Passador (2010), que fazem a reflexão de algumas políticas públicas da região tendo como ponto de partida este trabalho.

O coordenador dos estudos do GTDN e, em seguida, primeiro presidente da SUDENE, sob indicação do presidente Juscelino Kubitschek, o economista Celso Furtado, creditou esta iniciativa do Estado como sendo resultado de uma convergência de fatores políticos que propiciaram ao Nordeste ser pensado racionalmente, o que colocava em marcha a possibilidade de mudanças estruturais da organização econômica e política, assim confrontando o poder local, "coronelístico", que se assentava em formas arcaicas de exploração da terra e do trabalho. Uma experiência que foi interrompida com o golpe militar de 1964, que obstaculizou a marcha civilizatória, ao promover um retrocesso político que tornou as instituições estatais prisioneiras das velhas lideranças políticas oligárquicas. Uma estratégia dos militares que, em troca da sustentação da ordem política imposta, abriu espaços na administração pública para indicações dos senhores latifundiários. Com efeito, as ações estatais passaram a legitimar a concentração de renda e distância social, que o GTDN diagnosticara como sendo resultante, principalmente, da estrutura fundiária concentrada e da baixa incidência do trabalho assalariado.

Furtado (1989) descreveu a economia do Nordeste que a SUDENE procurou transformar como sendo um sistema de baixa produtividade e dependente do comércio exterior. Historicamente se constituiu no Nordeste dois pólos de produção; sendo um - economia de centro - de exploração agrícola na faixa litorânea voltada para a exportação; e, outro - economia periférica - dedicado à produção de animais de carga e para a alimentação, com o intuito de abastecer o primeiro pólo, sendo complementado com a produção de subsistência alimentar. No primeiro pólo, o trabalho escravo era parte do capital dos empreendimentos, que, nas fases de redução de demandas do mercado externo, levava as empresas a optarem pela redução da mão-de-obra livre, com o objetivo de diminuir as despesas e manter as taxas 
de lucro. Esta força de trabalho liberada engrossava a mão-de-obra ocupada na economia periférica, assim reduzindo ainda mais a produtividade deste pólo e, simultaneamente, ampliando sua importância demográfica.

Entretanto, como a expansão das oportunidades de trabalho era mais elevada na economia de subsistência, este pólo funcionava como lócus de absorção de excedente de mão-de-obra do setor exportador, que a partir do século XIX passou a se confrontar com uma permanente redução do seu mercado consumidor. Desta forma, engendrou-se uma economia regional com fluxos entre os dois pólos, onde a crise de exportação que se abatia crescentemente sobre as empresas da faixa litorânea reduzia as taxas de lucro ea renda do trabalho assalariado; porém, na economia de subsistência, assistia-se a uma degradação crescente das condições de sobrevivência, o que provocava um empobrecimento médio da região.

Considere-se ainda, na configuração econômica do Nordeste, a singularidade de que quanto mais a necessidade foi expandindo a exploração das terras mais afastadas do litoral, ou seja, quanto mais se avançou em direção ao sertão - corruptela de "desertão" - mais foi se praticando uma agricultura em áreas de baixos índices pluviométricos, o que foi expandindo a economia de baixa produtividade na região. Porém, floresceu na economia de subsistência, como salienta Furtado (1989), a produção de mercadorias direcionados para exportação, principalmente algodão e oleaginosas, um fator que contribuiu para um aprofundamento da distância social existente nesta área onde a produtividade é mais baixa. Isto porque o binômio algodão-pecuária se assentou no latifúndio, de sorte que se ocuparam as maiores e as melhores faixas de terras para a exploração das mercadorias geradoras de lucros mais elevados, enquanto a mão-deobra excedente se localizava em faixas de terras de baixa produtividade especializando-se na produção de alimentos. E, em função da concentração da terra, muitos exerciam esta atividade na terra de outros, sendo remunerado na forma de parceria, percebendo um terço ou metade da produção.

O crescimento demográfico combinado com a estrutura fundiária, marcada pela posse de latifúndios nas mãos de poucos proprietários, foi robustecendo as mazelas provocadas nas grandes estiagens, que a partir do século XIX ganhou visibilidade nacional. O problema da seca, que arrastava contingentes populacionais expressivos para a condição de miséria e fome tornou-se uma "questão social" a ser enfrentado pelo poder público. As ações invariavelmente se davam por intermédio das chamadas "frentes de trabalho", onde levas de trabalhadores eram alocadas para a realização de serviços de construção de barragens e açudes, normalmente realizados nas grandes propriedades; ou ainda, na prestação de serviços outros, normalmente ligados aos interesses dos grandes proprietários, como estradas vicinais ou obras que facilitassem a estocagem e o escoamento da produção.

Nesta perspectiva, a ação estatal não alterava as características do sistema econômico da região, uma vez que favorecia a acumulação de poder dos donos dos latifúndios. Tem-se na intervenção do Estado para solucionar o problema da seca uma contribuição para aprofundar os problemas na região que, de acordo com Furtado (1989, p. 23), são originados por uma combinação onde "o ecológico, o econômico, o social e o político se entrelaçaram para produzir o duro cimento em que se alicerçou o subdesenvolvimento do Nordeste." Concretizou-se a resistência das regras informais e sua sobreposição as regras formais, como assevera Gico Júnior (2017), ao esclarecer que o arcabouço ou ambiente institucional se trata do conjunto de órgãos e regras acrescidos de hábitos e costumes enraizados, de tal maneira que este arcabouço é resultante da história de uma sociedade. Assim sendo, o sentido empregado ao ambiente institucional se dá por intermédio do emprego das forças das elites que estruturam as instituições fundamentais visando perpetuarem-se no poder.

O governo de Kubitschek compreendeu que os problemas do nordeste estavam muito além do fenômeno da seca. Enxergou as mazelas causadas pela estiagem como sendo consequência da forma como a terra havia sido ocupada, do modelo de exploração dos recursos que fora adotado e do exercício do poder, que favorecia a apropriação extremamente desigual e retida nas mãos de uma minoria, além de funcionar como garantia para a reprodução das condições de exploração e de sobrevivência da região. Furtado (1989) explicita que diante desta compreensão partiu-se para a estruturação de uma nova política 
de desenvolvimento para o nordeste, que não se resolveria com a criação de mais um órgão público. Assim, juntamente com a SUDENE instala-se um novo modelo gerencial e operacional de ação do Estado, ou seja, as ações passaram a ser pensadas de forma de um Plano Diretor plurianual, concebidas com a participação de todos os órgãos envolvidos; portanto, tanto o planejamento como a execução seriam realizadas de maneira descentralizada, a partir da coordenação da SUDENE que funcionaria com base nas diretrizes formuladas pelo seu Conselho Deliberativo.

Os esforços para a realização deste empreendimento demandavam desde questões de ordem política, com a necessidade da organização de uma frente regional para articular no Congresso Nacional a defesa dos interesses da região, atéas de ordem pragmáticas, como a formação de quadros para uma atuação técnica especializada. Fatores necessários à elaboração e implantação de uma política de industrialização, que atendesse

Ao triplo objetivo de dar emprego a essa massa de subempregados, de criar uma classe dirigente imbuída do espírito de desenvolvimento e de fixar na região os capitais formados em outras atividades econômicas que atualmente tendem a migrar. (FURTADO, 1989, p. 55).

O pressupostoaí presenteseriaa redução da participação da agricultura desubsistência na economia e na retenção da força de trabalho, objetivo que seria complementado com a abertura de uma fronteira agrícola na faixa subamazônica maranhense, tencionando a absorção da força de trabalho do semiárido e uma melhor adequação demográfica. A combinação destes objetivos almejava, simultaneamente, um aumento da monetarização da economia e uma ampliação da produtividade em todos os setores.

Araújo (1984), ao analisar os efeitos das ações da SUDENE, no concernente ao desenvolvimento do Nordeste, afirma peremptoriamente, com base no desempenho das décadas de 1960/1970, que se verificou um hiato entre o acontecido e o proposto pelo GTDN. Uma reflexão sobre o resultado das políticas públicas desenvolvimentistas deve, sobremodo, considerar que as ações direcionadas para o desenvolvimento do Nordeste focaram principalmente o fomento da produção industrial, embora a agricultura tenha sido alvo de ações modernizantes.

Neste sentido, vale averiguar os efeitos da intervenção estatal no período que antecedeu a promulgação da Constituição de 1988, ou seja, examinar o que legou os militares que, no seu transcurso de exercício de poder, herdou dos governos que lhe antecederam um diagnóstico das causas impeditivas ao desenvolvimento da região, bem como um receituário das ações necessárias para se promover a alteração das condições que aprisionavam o Nordeste na reprodução de uma apropriação radicalmente desigual da riqueza e, portanto, da retenção de expressivo contingente populacional na condição de pobreza.

Em termos práticos, nos anos 1950, concluiu-se que se fazia necessária a implantação de uma produção siderúrgica e, por conseguinte, de aço e de ferro; decorrente desta assertiva, propugnava-se o fomento de atividades de transformação destas matérias, por exemplo, levantava-se a necessidade do incentivo à produção de implementos agrícolas e de móveis metálicos. Também é importante observar, como fora proposto pelo GTDN, se foi gerado uma indústria direcionada à transformação dos recursos regionais; assim como, se estas iniciativas desencadearam um efeito multiplicador alcançando os setores industriais já existentes, como o têxtil e confecções, além das atividades de serviços auxiliares. Enfim, estas proposições, dentre outras, foram implantadas e alcançaram os objetivos projetados?

De modo geral, afirma Araújo (1984) que o crescimento industrial do Nordeste alcançou a taxa média, nos anos 1970, de $9 \%$ ao ano. Também, assistiu-se uma diversificação do parque industrial, o que pode ser verificado por intermédio dos setores que mais captaram investimentos do FINOR. Segundo a autora, destacam-se dentre as atividades não tradicionais a indústria química (30\%), metalúrgica (16\%), minerais não metálicos (7\%); já nos segmentos tradicionais, observou-se que a indústria têxtil $(15 \%)$, alimento (10\%) e a de vestuário e calçados (3\%) aparecem como as mais beneficiadas pelos investimentos oriundos do FINOR. 
Como os investimentos se direcionaram, em mais larga escala, para os setores não tradicionais, percebeu-se uma mudança na composição da produção industrial, de sorte que, em 1960, a contribuição das indústrias tradicionais para o Valor da Transformação Industriais (VTI) do Nordeste que era de $75 \%$ passou, para 50\%, em 1980. Em contrapartida, entre 1950 e 1975, verificou-se uma redução da participação da produção de bens de consumo não duráveis, que diminuiu de $83 \%$ para $48 \%$ sua participação.

Em suma, pode-se afirmar que houve avanço na industrialização do Nordeste, que aumentou e diversificou a produção. Entretanto, não se gerou uma industrialização autônoma na região, que se consolidou como sendo marcadamente dependente e complementar, em relação à industrialização brasileira sob o comando do Sudeste. Na verdade, uma dependência que se realiza em função da origem dos recursos financiadores, dos mercados para onde se dirigem a produção e no concernente à aquisição dos equipamentos de produção.

Têm-se ainda, como característica da produção industrial do Nordeste estruturada no período anterior a Constituição de 1988, o fato de que do total do capital integralizado dos investimentos realizados somente $26 \%$ são originários da própria região. Isto ocorreu devido ao capital com potencial para participar dos incentivos fiscais do FINOR estarem concentrados no Sudeste, o que resultou numa industrialização subordinada aos interesses do capital aí localizado. Como decorrência, construiu-se uma matriz de produção em que o mercado destinatário, em 1980, estava constituído da seguinte forma: "mercado nacional 43\% (sendo $25 \%$ para São Paulo) e mercado internacional, $15 \%$. Acrescente-se que apenas $10 \%$ das empresas produzem exclusivamente para o mercado nordestino". (ARAÚJO, 1984, p. 75).

Em 1980, quando o país caminhava para o fim da ditadura militar, para a abertura política, para a democratização, para eleições livres e diretas, enfim, para a Assembleia Nacional Constituinte de 1987/1988, pode-se dizer que havia um quadro da produção industrial, comparado aos anos 1950, que pode ser definido como mais elevada e diversificada. Entretanto, o esforço realizado não reduziu o hiato que separava o Nordeste do Sudeste, em termos de geração de riqueza. E, principalmente, a intervenção do Estado não foi capaz de alterar as condições de sobrevivência na região. Como esclarece Araújo (1984), a renda média do Nordeste continuava, como nos anos 1960, num patamar inferior à renda média do Brasil, o Nordeste ainda apresentava o mais alto grau de concentração de renda do país e mais da metade dos trabalhadores $(53 \%)$ percebiam um rendimento mensal de até um salário mínimo.

\section{A CONSTITUCIONALIZAÇÃO DO DESENVOLVIMENTO REGIONAL: PROPOSIÇÕES E RESULTADOS}

A ação do poder estatal quanto à obrigatoriedade de planejar e executar políticas públicas, no intuito de atender as determinações dos princípios constitucionais, adquiriu teor normativo na Constituição de 1988, tornando-se exigível o seu cumprimento enquanto dever legal. Eros Grau (2005) é conclusivo na afirmação de que produzimos um ordenamento constitucional dirigente, em que Estado e sociedade encontram-se compelidos a realizar um plano global constituído de programas e diretrizes que, em última instância, almeja a implantação de uma nova ordem. Oliveira (2008) esclarece ainda que já no preâmbulo da Constituição está explicito como dever do Estado brasileiro assegurar, dentre outros valores supremos, o desenvolvimento.

Mas é preciso observar que, ao administrador público, está dado o recurso à reserva de discricionariedade no concernente ao gerenciamento dos recursos estatais e, por consequência, na priorização da efetivação das políticas públicas. Entretanto, vale enfatizar que o exercício da administração pública direta ou indireta, relativa aos poderes federal, estadual ou municipal, de acordo com o que está explicito no artigo $37^{\circ}$, CAPUT, da Constituição da República Federativa do Brasil, afirma a necessidade de obediência aos "princípios de legalidade, impessoalidade, moralidade, publicidade e eficiência".

Bustamante (2010) salienta que os princípios devem ser cumpridos de forma a maximizar sua aplicabilidade, a despeito de limitações fáticas interpostas pelos casos concretos. Ou seja, a administração 
pública deve obrigatoriamente obedecer à lei, não podendo agir com total discricionariedade na tomada de decisões, mas sim fundamentado no que explicita a norma. Depreende-se do pensamento de Sena Segundo (2007), que, já considerando o parâmetro da discricionariedade, resta ao Estado e agentes públicos os limites da ação referenciada na regulamentação, uma vez que podem incorrer no exercício de inconstitucionalidades. Por sua vez, o princípio da impessoalidade conduz o Estado e seus agentes à execução de ações exclusivamente pautadas no caráter da impessoalidade, de sorte que deva prevalecer o interesse da coletividade sobre o de particulares, assim como a administração pública não deva discriminar um caso e sobrepô-lo a outro. Já o princípio da moralidade pressupõe a ação do poder púbico sob o viés da ética e do zelo com a república, de sorte a obstaculizar ameaças ao erário e a lisura do exercício das atividades e cargos públicos. E os preceitos norteadores do funcionamento da administração pública, que devem ser observados no sentido de se alcançar o máximo de eficiência do quadro institucional e seus serviços, dão forma ao princípio da eficiência.

Ao destacar os princípios concernentes à questão econômica, particularmente os relativos à criação de políticas públicas, é precípuo mencionar o que está disposto no artigo 170 da Constituição da República do Brasil de 1988, mais precisamente no inciso VII, no qual pontilha a obrigatoriedade de se envidar esforços objetivando a "redução das desigualdades regionais e sociais". À luz destes prolegômenos, que tratam dos princípios que regem a atuação do poder público em todas as suas esferas e finalidades, bem como dos referentes ao combate das desigualdades regionais e sociais, far-se-á uma reflexão acerca das ações estatais e seus resultados. Com efeito, os princípios aqui elencados constituem-se em elementos essenciais, como entende Sena Segundo (2007, p. 396), para se alcançar "a eficácia social e material das normas fins que fundamentam a estrutura da ordem constitucional".

Mais precisamente, acerca dos dispositivos constitucionais concernentes ao desenvolvimento regional, depreende-se do Artigo $3^{\circ}$, inciso III, que se trata de objetivo fundamental da República do Brasil "a erradicação da pobreza, da marginalização e a redução das desigualdades sociais regionais". Com efeito, um arcabouço normativo que cimentou a base sobre a qual se erigiram leis complementares, como a Lei da erradicação da pobreza, no 111, onde está prescrito em seu CAPUT do artigo ํㅜ:

Art. $1^{\circ}$ O Fundo de Combate e Erradicação da Pobreza, criado pelo art. 79 do Ato das Disposições Constitucionais Transitórias - ADCT, para vigorar até o ano de 2010, tem como objetivo viabilizar a todos os brasileiros o acesso a níveis dignos de subsistência e seus recursos serão aplicados em ações suplementares de nutrição, habitação, saúde, educação, reforço de renda familiar e outros programas de relevante interesse social, voltados para a melhoria da qualidade de vida.

A promoção da equidade entre os Estados está recepcionada na Constituição de 1988, no artigo $4^{\circ}$, onde este princípio está explicitado e se presta, grosso modo, a nortear a administração estatal na elaboração e condução das políticas públicas. O artigo 174, por sua vez, fundamenta o papel do Estado que, enquanto agente regulador da atividade econômica, deve exercer, "na forma da lei, as funções de fiscalização, incentivo e planejamento sendo este determinante para o setor público e indicativo para o setor privado". Deduz-se daí a atribuição de uma dupla função ao Estado, ou seja, a de fiscalizar os atos das empresas públicas e privadas e a de fomentar o incentivo destas visando o desenvolvimento das regiões. Têm-se neste pressuposto um elemento de suma importância para a efetividade da intervenção do Estado, como esclarece Barral (2007), no concernente à promoção do desenvolvimento, ou seja, que os poderes públicos consigam realizar uma intervenção que não provoque obstáculos as ações da livre iniciativa.

A indagação que Paulo Bonavides (2002) se coloca quanto à constatação de ser a Constituição de 1988 uma constituição do Estado social trata-se de uma inquietação que nos permite aferir se estamos diante de um regime capaz de possibilitar o desenvolvimento do Brasil e, mais precisamente, do Nordeste, numa escala que conduza a superação das condições históricas que aprisionam esta região na situação de atraso econômico e pobreza socioeconômica. Defende o jurista que a Constituição de 1988 traz em muitas de suas dimensões caracteres que lhe atribuem o status de uma Constituição de Estado social; 
sobretudo, avançou na perspectiva da garantia dos direitos sociais, produziu-se uma Carta em que se instituiu o mandato de injunção, o mandato de segurança coletivo e a inconstitucionalidade por omissão. "O Estado social brasileiro é, portanto, de terceira geração, em face desses aperfeiçoamentos: um Estado que não concede apenas direitos sociais básicos, mas os garante." (BONAVIDES, 2002, p. 338).

Percorrendo uma linha histórica e, inicialmente, salientando uma ação no âmbito da educação, ressalte-se que, em 2005, foi regulamentado o Programa Universidade para Todos (PROUNI), sob a Lei 11.096, de 13 de janeiro de 2005, que viabilizou a oferta de bolsas parciais e integrais aos alunos dos cursos de graduação em instituições privadas no ensino superior. Araújo (2017, p. 552), ao comentar sobre o desenvolvimento recente do Nordeste, ressalta este Programa como exemplar na melhora dos índices educacionais do país, uma vez que "o Censo Demográfico de 2000 e o de 2010 mostraram que o número de pessoas com o ensino superior completo mais que dobrou, passando de 5,9 milhões pra 13,5 milhões de pessoas".

No ano de 2012, irrompeu, no conjunto normativo brasileiro, outra ação expressiva para a melhoria das condições de vida da população nordestina; por intermédio do Decreto 7.535, de 26 de julho de 2011, instituiuse o Programa Nacional de Universalização do Acesso e Uso da Água, que objetiva a democratização do acesso à água na zona rural, visando ao consumo humano, à produção agrícola e alimentar. Este programa, embora dirigido a todas as famílias nas diferentes regiões do país, pretende alcançar, preferencialmente, as famílias inseridas na agricultura de subsistência nas áreas secas do Nordeste.

A avaliação centrada no Nordeste, sem comparações com as demais regiões, leva a constatação de que ocorreu uma melhoria tanto na economia quanto na qualidade de vida das pessoas. Como aponta Araújo (2017), verificou-se um crescimento do Produto Interno Bruto (PIB) na primeira década do século XXI e, ao mesmo tempo, assistiu-se a uma redução do número de pessoas na situação de miséria. A autora chama a atenção para o fato de que, apesar da escassez de chuvas acima da média histórica, neste mesmo período não se verificou registro de saques no comércio das cidades do interior, nem das levas de mendicantes nas estradas, como se via anteriormente em épocas de estiagens prolongadas.

Para Araújo (2017), contribuiu para esta conjuntura, a adoção de uma política de ampliação de crédito para os pequenos e médios produtores urbanos e rurais, iniciada no Governo de Lula da Silva e complementada no Governo de Dilma Rousseff, combinada com políticas públicas voltadas para a melhoria da educação e para a segurança alimentar, questões basilares e imprescindíveis para as ações de fomento ao crescimento econômico e ao desenvolvimento social, além de uma larga política de transferência de renda, que tem como base o Programa Bolsa Família. A pesquisadora argumenta que o desenvolvimento do Nordeste pode ser observado nos dados da Pesquisa Nacional de Amostra de Domicílios (PNAD), em que se destaca positivamente na avaliação dos indicadores sociais, para os anos de 1995 a 2005, o desempenho da área de saúde, de educação e de renda.

O Banco Mundial (BM), em relatório sobre a educação brasileira, que compreende o período de 1995 a 2010, avalia as reformas educacionais implantadas nos dois mandatos dos governos de Fernando Henrique Cardoso e de Lula da Silva. De acordo com (MOTA JÚNIOR; MAUÉS 2014), o BM faz uma avaliação positiva e destaca a ocorrência de avanços nestes 15 anos. O banco salienta, principalmente, que os esforços empreendidos neste período colocaram o Brasil no caminho para atender as metas de qualidade da Organização para a Cooperação e o Desenvolvimento Econômico (OCDE) para 2021. Este balanço positivo se assenta, principalmente, nas estatísticas educacionais que indicam o aumento do número médio de anos de estudo para o conjunto da população brasileira, particularmente entre os segmentos populacionais mais carentes; por último, o BM chamou a atenção ainda para o aumento da escolaridade da força de trabalho, a elevação do nível de formação dos professores e os resultados dos estudantes brasileiros no Programme for International Student Assesstment (PISA).

Dentre as menções de ações exitosas feitas pelo Banco Mundial (BM), segundo (MOTA JÚNIOR; MAUÉS 2014), encontram-se os mecanismos de avaliações adotados nos governos de Cardoso e de Lula (SAEBE, Prova Brasil, IDEB, ENEM, Provão, ENADE), que se constituíram em importantes instrumentos 
de orientação às ações técnicas e financeiras. Entretanto, o BM foi crítico nas ponderações concernentes à dotação de recursos públicos para a área educacional, ao considerar insipiente os investimentos realizados no ano 2000 e muito aquém das necessidades reais o aumento de 1,2\% do PIB no orçamento educacional realizado na década posterior.

Com efeito, constatam-se avanços tanto na perspectiva legislativa quanto na proposição de políticas públicas, mas as avaliações denotam que ainda persiste a necessidade de melhoria na educação. Na região nordeste esta é uma necessidade ainda mais acentuada. Silva e Almeida (2011) demonstram, com base nos dados do Censo Demográfico de 200o, por exemplo, a precariedade educacional do Nordeste, mesmo após as iniciativas estatais efetivadas; de tal maneira que, identificam no Nordeste, em 2000, que a média de estudo alcançava 4,52 anos, enquanto no estado de São Paulo atingia 6,86 anos, o que denota a insuficiência das ações realizadas para alterar a realidade socioeconômica desta região quando comparada com outras áreas do país.

Portanto, pode-se afirmar que o desenvolvimento ocorrido no Nordeste não foi capaz de reduzir mais fortemente o seu atraso em relação ao Sul e Sudeste. Araújo (2017) aponta, por exemplo, dados estatísticos que denotam uma precarização de suas condições socioeconômicas; ou seja, em 200o, a economia nordestina representava $12,4 \%$ da economia do país, embora tenham sido adotadas políticas de incentivo fiscal, de desenvolvimento da infraestrutura e sociais, em 2010, o Nordeste passou a compor a economia do país com uma representação de $13,4 \%$. Vê-se assim que, nesta região que detém $28 \%$ da população brasileira em seu território, ocorreu uma ampliação da sua participação na economia nacional de apenas um ponto percentual em dez anos. Quando se traz à reflexão o rendimento médio mensal domiciliar, percebe-se que o Nordeste ainda se encontra numa posição bem inferior em relação ao país, alcançando $70 \%$ da média nacional e, somente, $55 \%$ da média do sudeste.

O Brasil continua ainda hoje como um dos países mais desiguais do mundo. Nos anos 1980, alcançou patamar que o situava na décima segunda posição entre os países de piores índices de desigualdade, chegando mesmo a ficar atrás de Serra Leoa. Como afirma Gaulard (2011), o Brasil durante todo o século XX experimentou um aumento permanente da desigualdade regional e social, de sorte que a degradação do país em termos de desigualdade de renda, medida por intermédio do coeficiente de GINI³, não cessou nem mesmo nos períodos de robustos crescimentos econômicos, como na década de 1970. Foi somente a partir do início do século XXI que se assistiu uma inflexão desta tendência, de tal maneira que o Brasil passou de uma taxa de 0,593, em 2001, para 0,535, em 2009, um resultado positivo, em termos de redução das desigualdades entre os estratos populacionais, que ainda não foi observado em nenhum outro país do mundo. Sem dúvida que as ações estatais são responsáveis por este cenário, portanto, o marco normativo inaugurado com a Constituição de 1988 possibilitou uma intervenção do Estado exitosa na redução das desigualdades regionais e sociais.

Estudo do Instituto de Pesquisas Econômicas Aplicadas (IPEA), acerca da desigualdade de renda no Brasil, indica que a partir de 2001 até 2012, período enfocado na pesquisa, o país apresentou a maior redução de desigualdade, com base nos índices registrados desde os anos 1960. De tal maneira que entre 2001 a 2012, observou-se que a renda dos $10 \%$ mais pobres cresceu $550 \%$ mais que a dos $10 \%$ mais ricos. Concluíram os pesquisadores do IPEA que os rendimentos do trabalho foram responsáveis por $58 \%$ da queda do índice de Gini, $19 \%$ resultaram dos aumentos dos benefícios da previdência social e $13 \%$ se deveram à concessão do Bolsa Família. Apesar deste resultado positivo bastante significativo, de sorte a se constituir no melhor desempenho histórico, a desigualdade brasileira, em 2012, se encontrava entre as 12 mais altas do mundo.

O relatório de pesquisa do Instituto de Pesquisas Econômicas Aplicadas (IPEA), que trata da evolução da pobreza no Brasil, indica que entre 1995 e 2008, um contingente de 12,8 milhões de pessoas deixaram a condição de pobreza absoluta, entendida como rendimento médio domiciliar per capita de

3 O coeficiente de GINI mensura a desigualdade de renda entre os estratos populacionais, indicando que quanto mais próximo de zero melhor é a distribuição de renda e, inversamente, quanto mais o índice se encontra afastado de zero significa que há desigualdade mais acentuada, ou seja, uma má divisão da renda. 
até 0,5 salário mínimo. Este resultado levou a taxa de pobreza no Brasil passar de 43,4\% para 28,8\%, equivalente a uma redução de $33,6 \%$. Já na condição de pobreza extrema, quando o rendimento médio domiciliar per capita alcança no máximo 1/4 do salário mínimo, verificou-se uma saída 13,1 milhões de brasileiros para o mesmo período, que provocou uma redução de 49,8\% na taxa nacional.

Mas a taxa de redução, tanto para a pobreza absoluta como para a pobreza extrema, não se verificou de maneira uniforme para toda as regiões do país. Tomando como exemplos a Região Sul, Sudeste e Nordeste, tem-se que no Sul a taxa de pobreza absoluta caiu $47,1 \%$, no Sudeste $34,8 \%$ e no Nordeste 28,8\%; quando se observa a taxa de pobreza extrema, vê-se que no Sul a redução foi equivalente a 59,6\%, no Sudeste $41,0 \%$ e no Nordeste $40,4 \%$. Estes resultados fizeram com que a Região Nordeste apresentasse em 2008 as maiores taxas de pobreza absoluta $(49,7 \%)$ e de pobreza extrema $(24,9 \%)$; enquanto a Região Sul possuía as seguintes taxas: pobreza absoluta $(18,0 \%)$ e pobreza extrema $(5,5 \%)$; e a Região Sudeste alcançou respectivamente: pobreza absoluta $(29,9 \%)$ e pobreza extrema $(6,9 \%)$. O relatório do IPEA traz a informação de que os três estados com maior taxa de pobreza absoluta, em 2008, se encontravam na Região Nordeste, ou seja, Alagoas (56,6\%), Maranhão (55,9\%) e Piauí (52,9\%). Estes mesmos estados são também os detentores das maiores taxas de pobreza extrema, na seguinte ordem: Alagoas $(32,2 \%)$, Maranhão (27,2\%) e Piauí $(26,1)$.

A tabela 1 apresenta a quantidade de pessoas na condição de pobreza extrema, e os dados indicam, em números absolutos, o quanto é urgente a realização de esforços para combater os fatores que provocam este fenômeno social. Observa-se para o Nordeste uma quantidade equivalente a 3.450.627 pessoas sobrevivendo nesta situação, ou seja, uma taxa de $83,8 \%$ mais elevada do que o número de pessoas sobrevivendo nesta mesma condição na região Sudeste. Também, verifica-se que, aproximadamente, $50 \%$ dos brasileiros na condição de pobreza extrema residem no Nordeste.

TABELA 1 - Quantidade de pessoas na condição de Pobreza Extrema - 2014

\begin{tabular}{ll}
\hline Regiões & Quantidade \\
\hline Norte & 813.444 \\
Nordeste & 3.450 .627 \\
Sudeste & $\mathbf{1 . 8 7 7 . 2 9 1}$ \\
Sul & 403.415 \\
Centro-Oeste & $\mathbf{2 5 4 . 7 2 1}$ \\
\hline Brasil & 6.799 .502 \\
\hline
\end{tabular}

Fonte: Santos, 2017.

Os dados acerca das taxas de pobreza mostram que, para além do crescimento econômico, importante para se alcançar resultados significativos, faz-se necessária a adoção de políticas públicas que dinamizem a proteção social nos estados em que são mais substanciais os problemas sociais. Como explicita Cohn (1995), numa realidade como a brasileira, marcada por uma profunda desigualdade, em que se encontram contingentes populacionais na pobreza absoluta e na pobreza extrema, é preciso que se formule políticas e programas sociais direcionados para o alívio da pobreza e para a superação da pobreza. No primeiro caso, deve-se direcionar políticas imediatas, de caráter assistencialista, para atender as pessoas que se encontram na condição de alta vulnerabilidade. Já as políticas com o objetivo de promover a superação da pobreza devem ter um perfil de médio e de longo prazo, que estejam assentados numa perspectiva de desenvolvimento sustentável, portanto, que combine o crescimento econômico com equidade social.

Com efeito, a crítica dos estudiosos do desenvolvimento, como Silva e Almeida (2011), esclarece que para a promoção do desenvolvimento do Nordeste o entrave já não se encontra mais na ausência de diagnóstico e nem de legislação. Portanto, o que se faz necessário agora é transformar o que está idealizado em ações concretas, mas quantitativa e qualitativamente em acordo com a necessidade dimensionada, 
pois ainda há um fosso a ser transposto quando se observa as condições de vida dos que se encontram nos andares de baixo do edifício da estrutura social em relação aos que se encontram no topo.

Nesta linha de pensamento seguem pesquisadores longevos, como Celso Furtado (1999), em seus últimos escritos, e contemporâneos, dentre outros, Silva e Almeida (2011). Isto porque, como já observado, políticas públicas foram concebidase executadas, mas comvolumederecursose/ou abrangência de beneficiários ou cobertura espacial aquém do ideal para se promover um crescimento econômico e uma melhoria das condições de sobrevivência da população nordestina na velocidade e medida capazes de, no médio prazo, trazer o Nordeste para uma posição de maior equilíbrio com as regiões mais desenvolvidas do país.

\section{CONSIDERAÇÕES FINAIS}

A representação do Nordeste miserável foi uma criação que se erigiu na massa de desvalidos formados pelos pequenos sitiantes e agricultores sem-terra atingidos pelos efeitos danosos do fenômeno das secas, que se reproduziam num ciclo que arrastava para a miséria e pobreza absoluta um contingente populacional sempre crescente. Têm-se nesta idealização do Nordeste a identificação das longas estiagens como sendo a causa determinante das mazelas que atingem renitentemente seus habitantes. Uma construção que nasceu na literatura, alcançou a consciência coletiva nacional e influiu no pensamento técnico-científico. As ações do Estado na região, das primeiras intervenções imperiais até a modernidade inaugurada pelo getulismo, centraram-se na tentativa de amenizar os efeitos nefastos das secas. Porém, a estrutura de poder, que se assentava no mandonismo autoritário de proprietários de latifúndios, produtores agrícolas e pecuaristas, dominantes dos cargos e funções públicas, revertiam as ações do Estado em benefício próprio, o que garantia a reprodução do sistema de expropriação do trabalho e do poder patriarcal, exercidos pelos "coronéis" do sertão e "barões" do açúcar.

A criação da Companhia Hidro e Elétrica do São Francisco (CHESF), no Governo de Getúlio Vargas, é uma primeira ação estatal significativa na busca de dotar o Nordeste de uma infraestrura industrial, portanto, que não estava diretamente vinculado aos interesses dos exportadores açucareiros e algodoeiros, nem dos pecuaristas. Entretanto, a proposição de um conjunto de ações articuladas, tencionando uma mudança radical na estrutura produtiva da região, veio com a formação do Grupo de Trabalho para o Desenvolvimento do Nordeste (GTDN), que, nos anos 1950, trouxe ao lume um diagnóstico técnico-científico, ao mesmo tempo, preciso na identificação dos problemas econômicos e ambientais e criativo na formulação de ações estratégicas, que almejavam o aumento da produtividade econômica, da formalização do mercado de trabalho e da circulação de fluxos monetários. A racionalidade do trabalho do GTDN colocava em xeque a estrutura do poder local, pois propunha uma priorização das atividades e ações a serem realizadas a partir de um amplo debate, com técnicos de diversos órgãos federais e estaduais, o que resultaria na formulação de um Plano Diretor.

O advento da ditadura militar arrefeceu os impactos da implantação das ações propostas no relatório do GTDN, uma vez que se verificou um alinhamento das forças locais, ou seja, das velhas lideranças oligárquicas, com o poder central. Apesar disto, se verificou a implantação de parte das ações propugnadas, principalmente aquelas direcionadas para a industrialização, de sorte que ocorreu um aumento do Produto Interno Bruto (PIB) da região, mas manteve-se intacto os mecanismos geradores da acumulação de riquezas nas mãos de uma minoria e a reprodução de uma massa de trabalhadores com salários irrisórios; assim, não se constituindo um mercado consumidor relevante e nem irradiando os efeitos positivos da dinâmica da produção industrial sobre os demais setores da economia.

Eis os elementos impulsionadores dos debates na constituinte de 1987/1988, extremamente acirrados, como lembra Eros Grau (2005), acerca do combate à desigualdade regional e à pobreza. Criouse, enfim, uma regulamentação extremamente favorável às ações estatais promotoras do desenvolvimento. A Constituição de 1988, caracteristicamente de Estado social, formulou uma garantia de direitos sociais 
que se mostraram capazes de alterar a estrutura social radicalmente desigual existente no Brasil e, principalmente, no Nordeste.

Contudo, as análises de dados estatísticos, apresentados por instituições nacionais einternacionais, bem como por pesquisadores de diversas áreas, demonstram que ainda se faz necessário um esforço hercúleo para se promover justiça social no Brasil e no Nordeste, sobretudo, que se demanda uma forte luta política a cada novo contexto legislativo para que se garantam os recursos necessários e a sua aplicação racional e destituída de interesses políticos historicamente enraizados numa tradição patriarcal.

\section{REFERÊNCIAS:}

ANDRADE, Manuel Correia de. A terra e o Homem no Nordeste. São Paulo: Editora Atlas, 1986.

ARAÚJO, Tânia Bacelar de. Industrialização do Nordeste: intenções e resultados. In: MARANHÃO, Silvio. A Questão Nordeste: estudos sobre formação histórica, desenvolvimento e processos políticos e ideológicos. Rio de Janeiro: Paz e Terra, 1984.

. Nordeste: Desenvolvimento recente e Perspectivas. Biblioteca Digital/ BNDES. Disponível em: <http://www.afbnb.com.br/arquivos/File/apoio2\%2047\%2orcr.pdf.> Acesso: em 25 nov. 2017.

ARRUDA, Gerardo Clésio Maia. Andarilhos do Sertão: a mudança do padrão de comportamento do trabalhador rural na cidade do semiárido nordestino. Tese de Doutorado. Fortaleza: Universidade Federal do Ceará, 2003.

Trabalho, Riqueza e Dominação no Sertão do Nordeste do Brasil. Salvador: Caderno do CEAS, n. 219, p. 43-62, set-out/2005.

BARRAL, Welber. As relações entre Direito e Desenvolvimento. Canoas: Revista Direito e Democracia, v. 8, n. 2, p. 214-238, jul-dez/2007.

BASTIDE, Roger. Brasil: terra de contrastes. São Paulo: Difusão Europeia do Livro, 1959.

BONAVIDES, Paulo. Curso de Direito Constitucional. São Paulo: Malheiros Editores Ltda, 2002.

BRASIL. Decreto-Lei no 8.486, de 28 de dezembro de 1945. Dispõe sobre a reorganização da Inspetoria Federal de Obras Contra as Secas (IFOCS). Rio de Janeiro, dez 1945. Disponível em: <http://www.planalto. gov.br/ccivil_03/decreto-lei/1937-1946/Del8486.htm > Acesso em: 20 dez. 2017.

Decreto-Lei. no 8.031, de 03 de outubro de 1945. Autoriza a organização da Companhia Hidro Elétrica do São Francisco. Rio de Janeiro, out 1945. Disponível em: <http://www.planalto.gov.br/ ccivil_03/decreto-lei/Del8031.htm.> Acesso em: 20 dez. 2017.

Decreto-Lei no 1.649, de 19 julho de 1952. Cria o Banco do Nordeste do Brasil. <http://www. planalto.gov.br/ccivil_03/leis/1950-1969/L1649.htm. > Acesso em: 20 dez. 2017.

Decreto-Lei. no 3.692, de 15 de dezembro de 1959. Institui a Superintendência de Desenvolvimento do Nordeste e dá outras providências. Rio de Janeiro, dez 1959. Disponível em: $<$ http://www.planalto.gov.br/ccivil_03/leis/1950-1969/L3692.htm.> Acesso em: 20 dez. 2017. 
Decreto-Lei. no 5.662, de 21 de junho de 1971. Enquadra o Banco Nacional de Desenvolvimento Econômico (BNDE) na categoria de empresa pública, e dá outras providências. Brasília, jun 1971. Disponível em: <http://www.planalto.gov.br/ccivil_o3/leis/L5662.htm. > Acesso em: 03 jan. 2018.

Decreto-Lei. no 1.367, de 12 de dezembro de 1974. Dispõe sobre a criação de Fundos de Investimentos, altera a Legislação do Imposto sobre a Renda relativa a incentivos fiscais e dá outras providências. Brasília, dez 1974. Disponível em: <http://www.planalto.gov.br/ccivil_03/decretolei/Deli376.htm.> Acesso em: 03 jan. 2018.

CONSTITUIÇÃO DA REPÚBLICA FEDERATIVA DO BRASIL Brasília: Edição Administrativa do Senado Federal, 2015.

Lei. no 11.096, de 13 de janeiro de 2005. Institui o Programa Universidade para Todos PROUNI. Brasília, jan. 2005. Disponível em: <http://www.planalto.gov.br/ccivil_03/_ato2004-2006/2005/ lei/l11og6.htm.> Acesso em o3 jan. 2018.

Lei. no 7.535, de 26 de julho de 2011. Institui o Programa Nacional de Universalização do Acesso e Uso da Água. Brasília, jul. 2011. Disponível em: <http://www.planalto.gov.br/ccivil_03/_ato20112014/2011/decreto/d7535.htm.> Acesso em: 03 jan. 2018.

Instituto de Pesquisa Econômica Aplicada (IPEA). Dimensão, evolução e projeção da pobreza por região e por estado no Brasil. Rio de Janeiro: IPEA, 2010.

. Instituto de Pesquisa Econômica Aplicada (IPEA). A década inclusiva (2001-2011): desigualdade, pobreza e políticas de renda. Rio de Janeiro: IPEA, 2012.

Departamento Nacional de Obras Contra as Secas (DNOCS). Relatório de gestão - 2015. Fortaleza, 2016.

BURSZTYN, Marcel. O poder dos donos: planejamento e clientelismo no Nordeste. Petrópolis: Vozes, 1984.

BUSTAMANTE, Thomas. Princípios, regras e conflitos normativos: um modelo para a justificação das decisões contra legem a partir da teoria jurídica de Robert Alexy. Revista Pensar, v.15, n. 2, p 603-627, jul.- dez./2010.

COHN, Amélia. Políticas sociais e pobreza no Brasil. Planejamento e Políticas Públicas, n. 12, p. 2-19, jan. - dez./1995.

CUNHA, Euclides da. Os Sertões. Rio de Janeiro: Francisco Alves, 1979.

FERREIRA, Angela Lúcia; SILVA, Déscio Rodrigo da Rocha e SIMININI, Yuri. A Produção Cartográfica da Inspetoria de Obras Contra as Secas e a Intervenção no Nordeste Brasileiro no Início do Século XX. Disponível em: <http//www.observatoriogeograficoamericalatina.org.>. Acesso em 25 dez. 2017.

FURTADO, Celso. A fantasia desfeita. Rio de Janeiro: Paz e Terra, 1989.

O longo amanhecer: reflexões sobre a formação do Brasil. Rio de Janeiro: Paz e Terra, 1999. 
Formação econômica do Brasil. São Paulo: Companhia das Letras, 2007.

GAULARD, Mylène. La lutte contre les inégalités au Brésil: une analyse critique de l'action du gouvernement de Lula. Mondes em développement, v. 156, no. 4, p. 111-128, 2011.

GICO JÚNIOR, Ivo Teixeira. Direito e desenvolvimento: o papel do direito no desenvolvimento econômico. João Pessoa: Revista Direito e Desenvolvimento, v. 8, n. 2, p. 110-127, 2017.

GRAU, Eros Roberto. A ordem econômica na Constituição de 1988. São Paulo: Editora Malheiros, 2005.

MOTAJUNIOR, William Pessoa da; MAUÉS, Olgaíses Cabral. O Banco Mundial e as políticas educacionais brasileiras. Revista Educação e Realidade, v. 39, n. 4, p. 1137-1152, 2014.

NOBRE, Geraldo da Silva. O processo histórico de industrialização do Ceará. Fortaleza: SENAI/DRCE, 1989.

OLIVEIRA, Francisco de. Elegia para uma Re(li)gião: SUDENE, Nordeste, planejamento e conflito de classes. Rio de Janeiro: Paz e Terra, 1981.

OLIVEIRA, Gustavo Justino. Direito ao desenvolvimento na Constituição brasileira de 1988. Brasília: Boletim de Direito Municipal, p. 737-749, 2008.

PASSADOR, Cláudia Souza e PASSADOR, João Luiz. Apontamentos sobre as políticas públicas de combate à seca no Brasil: cisternas e cidadania? São Paulo: Cadernos Gestão Pública e Cidadania, v. 15, n. 56, p. 65-86, 2010.

PEREIRA, Luiz Carlos Bresser. Economia brasileira: uma introdução crítica. São Paulo: Editora Brasiliense, 1988.

QUEIROZ, Raquel de. O quinze. São Paulo: Siciliano, 1993.

RAMOS, Graciliano. Vidas secas. São Paulo: Record, 1998.

SANTOS, Simone Torres Gusmão. Programa Bolsa Família: uma análise da evolução dos indicadores da pobreza relativa no Brasil. Dissertação de Mestrado. Montes Claros: Universidade Federal de Minas Gerais, 2017.

SENA SEGUNDO, Oswald de Andrade. O princípio constitucional da redução das desigualdades regionais e sociais e sua efetivação jurídico-política na ordem econômica. Revista da Direito e Liberdade, Mossoró - RN, v.7, n.3, p.371-40o, jul./dez. 2007.

SILVA, Alexandre Manoel Ângelo da; ALMEIDA, Mansueto. Desafios de uma nova política regional para o Nordeste. Boletim regional, urbano e ambiental, 5 de junho de 2011.

SOUZA, Clemente Gomes et.al. Instituições, políticas públicas e financiamento do desenvolvimento regional no Nordeste do Brasil. Salvador: Anais VIII Encontro de Economia Baiana, p. 591-608, set./2012. 